\title{
Increasing Haemodialytic Clearances as Residual Renal Function Declines: An Incremental Approach
}

\author{
Kamonwan Tangvoraphonkchai ${ }^{a}$ Andrew Davenport ${ }^{\mathrm{b}}$ \\ ${ }^{a}$ Faculty of Medicine, Mahasarakham University, Mahasarakham, Thailand; ${ }^{b}$ UCL Centre for Nephrology, Royal Free \\ Hospital, University College London, London, UK
}

\section{Keywords}

Haemodialysis $\cdot \mathrm{Kt} / \mathrm{V} \cdot$ Incremental $\cdot$ Residual renal function

\begin{abstract}
Many patients with chronic kidney disease start undergoing thrice-weekly haemodialysis (HD), aiming for an HD sessional dialyzer urea clearance target, irrespective of whether they have residual renal function (RRF). While increasing sessional dialyzer urea clearance above a target of 1.2 has not been shown to improve patient survival, it has been shown that the preservation of RRF improves patient self-reported outcomes and survival. Observational studies have suggested that initiating twice-weekly HD schedules leads to greater preservation of RRF. This has led to the concept of following an incremental approach to initiating $H D$, steadily increasing the amount of weekly dialyzer clearance as RRF decreases. Incremental dialysis practice requires the regular assessment of RRF to prevent inadequate delivery of dialysis treatment. Once RRF is lost, then the dialysis schedule and modality need to be adjusted to try to increase the middle-sized solute clearance and protein-bound toxins.
\end{abstract}

(C) 2017 S. Karger AG, Basel

\section{Introduction}

Haemodialysis (HD) is currently the most accepted life-saving treatment for patients with end-stage renal disease worldwide [1]. Based on an initial trial that recruited a relatively small number of patients, urea clearance adjusted for the volume of urea distribution (Kt/Vurea) has become the basis for the delivery of HD dialyzer clearance for patients [2]. Patients receiving thrice-weekly HD sessions achieving a single pool $\mathrm{Kt} /$ Vurea of $<0.9$ were more likely to be withdrawn from the National Cooperative Dialysis Study (NCDS) study, and as such a minimum sessional target of $>1.0$ was suggested, which was later increased to 1.2. However, a further study, that is, the HEMO study, failed to demonstrate a survival advantage for a higher sessional dialyzer $\mathrm{Kt} /$ Vurea target $[3,4]$. As these studies had recruited prevalent rather than incident patients, none had included measurements of the residual renal function (RRF). This has led to a clinical practice of starting most incident HD patients on a thrice-weekly HD schedule, aiming for a sessional urea clearance of $\geq 1.2$, irrespective of RRF.

Whether this dialyzer urea clearance target can be generalized to every HD patient irrespective of age, race, 
body size and composition, nutritional intake, physical activity, dialysis modality and RRF remains questionable. As the original NCDS trial recruited patients with little or no additional co-morbidity [5], the HEMO study included few patients weighing more than $100 \mathrm{~kg}$ [3]. Since an increase in sessional dialyzer urea clearance per se did not appear to increase patient survival, researchers turned their attention towards the clearance of middlesized molecules. However, a randomised control trial of high-flux dialysis failed to demonstrate improved patient survival (MPO) [6]. More recently, online HDF, which allows much greater convective exchange, has been introduced into clinical practice. Although there is controversy regarding whether online HDF does increase patient survival, as several of the individual trials failed to demonstrate an advantage, retrospective analysis of the pooled individual data was reported to show an overall survival benefit [7], especially when adjusted for body size [8].

Despite increasing convective clearances, online HDF effectively clears only water-soluble solutes. Accumulating data now suggests that protein-bound solutes have a role in causing cardiac and endothelial pathology [9]. Many of these protein-bound solutes are naturally excreted by the renal tubular organic acid transporters. Thus, the concentrations of these toxins are much lower in HD patients with RRF. Recent observational studies have suggested that patients initiating dialysis with less frequent dialysis schedules than the thrice-weekly traditional approach have greater preservation of RRF [10]. This has led from resurgence into an incremental approach to initiating dialysis. However, this approach also the requires the regular measurement of $\mathrm{RRF}$, and adjusting the amount of dialyzer clearance as RRF falls, and then when RRF has been lost to consider online HDF, or more frequent and longer HD schedules to improve azotaemic toxin clearance.

\section{Is There a Downside to Applying a Fixed Dialyzer Urea Clearance to All Patients?}

In 1960, dialysis adequacy was largely determined by controlling clinical symptoms such as malignant hypertension and peripheral neuropathy [11]. However, with the introduction of more reliable vascular access, regular thrice-weekly HD treatments became established as standard clinical practice based on clinical observations reporting increased patient stamina, reduced neuropathy and improved blood pressure control. Following the
NCDS report, the concept of urea clearance, adjusted for volume of urea distribution was introduced [2]. As such, the dialysis dose is quantified by a urea kinetic model based on pharmacokinetic principles. While the dosage and frequency of a maintenance dose for a drug are calculated by the rate at which the drug is cleared from its volume of distribution through metabolic and clearance pathways, urea kinetics is somewhat more complex. While drugs are used in fixed doses, urea generation depends upon dietary protein intake, particularly meat intake, muscle mass and physical activity and catabolic rate. In keeping with differences in urea generation, the mechanistic analysis of the NCDS reported no benefit in increasing the dialysis dose in patients with a protein catabolic rate of less than 0.8 [2]. Although for the HD patient dialyzer urea clearance accounts for a majority of urea clearance, there will be varying contributions from RRF and gastrointestinal losses. To allow comparison between patients, dialyzer urea clearance was adjusted to the volume of urea distribution, derived from equations based on anthropomorphic measurements. These equations were based on healthy, predominantly Northern Europeans, and excluded the morbidly obese. The introduction of bioimpedance techniques has shown that total body water measured by bioimpedance differs from that estimated by anthropomorphic measurements, due to changes in terms of age, gender, ethnicity and co-morbidity [12]. As such, using a single target Kt/Vurea for both HD and peritoneal dialysis patients leads to delivery of a lower effective dialysis clearance to women, men of short stature, patients with a lower body mass index and those who physically active with little or no-comorbidity [13]. On the other hand, as the estimated glomerular filtration rate (eGFR) of patients initiating HD has steadily increased over recent years, particularly in the United States, a thrice-weekly HD schedule targeting a sessional dialyzer urea clearance of $\geq 1.4$ for a patient with an eGFR of $\geq 10 \mathrm{~mL} / \mathrm{min}$ is not required. More frequent HD is not without its consequences, as intra-dialytic hypotension remains the most common complication of outpatient HD sessions, and repeated episodes of systemic hypotension and renal hypoperfusion potentially increase the risk of acute kidney injury and premature loss of RRF.

\section{Why Try and Preserve RRF?}

$\mathrm{RRF}$ is recognised as a major determinant of morbidity, mortality and quality of life for both HD and PD patients [14]. Patients with RRF benefit from less strict di- 
etary and fluid restriction. Preservation of RRF can potentially reduce sodium and water retention, resulting in improved blood pressure control, lower pulse wave velocity and reduction in left ventricular hypertrophy [15]. In addition, RRF increases middle-molecule and protein-bound solute clearances. A recently reported $\beta 2$-microglobulin $(\beta 2 \mathrm{M})$ kinetic study showed that any benefit of extracorporeal $\beta 2 \mathrm{M}$ clearance, whether by high flux HD, online HDF, more frequent short daily and/or long daily HD, was markedly reduced if RRF was still present [16]. In addition, both the more frequent haemodialysis network (FHN) trials did not show convincing evidence for greater middle-molecule or proteinbound solute clearances for those receiving more frequent dialysis schedules [17], and also some of the online HDF trials equally failed to demonstrate an advantage for middle-molecule [18] and protein-bound toxin clearances [19]. The apparent failure of more frequent and longer HD sessions and online HDF to increase middlemolecule clearances can be explained by including patients with RRF, so that any potential benefits of more frequent and longer HD sessions were offset by an increased loss of RRF with the more frequent and longer HD sessions [20].

\section{Can Too Much HD Be Detrimental?}

Three observational studies reported better preservation of RRF by initiating HD twice-weekly compared to standard thrice-weekly HD [21, 22]. The prospective FHN nocturnal trial reported greater loss of RRF in those patients who underwent dialysis 6 times per week compared to those dialyzing thrice-weekly. In the daily FHN trial, although there was a trend for more rapid loss of RRF with 6 times a week dialysis schedules, this was not statistically significant, but this may have been due to patient recruitment including patients with no RRF at baseline [20]. More frequent dialysis reduces time-average solute concentrations and extracellular volume, which normally promote urine output [23]. Reduction in extracellular volume may potentially predispose to episodes of acute kidney injury, and so cause more rapid loss of RRF. Moreover, more frequent exposure to the extracorporeal circuit leads to the activation of leukocytes and platelets and this inflammatory response may contribute to more rapid loss of RRF. As more frequent dialysis increases the number of access cannulations, this potentially results in risks leading to greater infection and non-infection-related access complications. The FHN daily trial reported an increased hazard ratio of 1.76 for the time to first access repair, access loss and access-related hospitalization in the more frequent dialysis group, with graft thrombectomy and revision being the commonest vascular access repairs [24]. The FHN nocturnal trial reported a similar trend, although differences were not statistically significant. Repeated trauma by access cannulation and in combination with turbulent blood flow can induce local inflammation with release of cytokines and growth factors, which stimulate neointimal hyperplasia and clot formation, resulting in access stenosis and thrombosis [25]. An Australian study also reported greater access complications, particularly infection for those patients treated with extended hours of HD, which significantly predicted death and technical failure [26].

Infection remains the leading cause of death and hospitalization for HD patients. HD patients are more susceptible to not only access-related but other forms of infection including respiratory tract infections, due to a combination of increased extravascular lung water, closer exposure to other patients and an altered immune system. HD patients not only have reduced responses to vaccinations, but also increased background pro-inflammatory state, characterised by increased interleukin 1, interleukin 6 and tumour necrosis factor- $\alpha[27,28]$ and complement on the one hand and downregulated interleukin 2 synthesis [29], ICAM-1 and TCR1/CD3 receptor expression on T-helper cells [30], and dysregulation of the Th1 and Th2 balance on the other, then impairs the response to pathogens [31]. Data from matched daily home and thrice-weekly in-centre cohorts reported a significant greater risk of first infection-related admission for the daily group [32].

Dialysis is unable to selectively regulate solute clearances. As such, more dialysis may potentially lead to vitamin and other deficiencies. Hypophosphatemia is a recognised and well-known complication of intensive dialysis. As expected, those patients undergoing dialysis more frequently in the nocturnal FHN trial required the addition of phosphorus into the dialysate to prevent hypophosphatemia [33].

More frequent dialysis increases the time spent on dialysis, which may increase travelling times to and from dialysis, time to set up and clear away, thereby reducing the quality of life. In addition, the loss of RRF imposes greater dietary and fluid restrictions. Neither the daily nor the nocturnal FHN trials were able to demonstrate that more frequent dialysis improved the quality of patient life. On the other hand, observational studies have reported better patient-reported quality of life for those 
patients initiating HD with a twice-weekly schedule compared to thrice weekly $[34,35]$. A propensitymatched study also reported better quality of life and less self-reported depression in patients initially undergoing dialysis twice weekly and then increasing dialysis frequency as RRF was lost, although by 12 months differences were no longer significant [36]. Moreover, more frequent dialysis sessions have an impact not only on the patient but also places increased stress on the spouse, partner, or family.

\section{Should All Patients Start on Twice-Weekly HD Schedules?}

On the contrary, inadequate dialysis is potentially harmful for patients with insufficient RRF. The report from NCDS recommended against a sessional Kt/Vurea below 0.9 for thrice-weekly HD schedules, as it was associated with increased risk of hospitalization and morbidity [2]. Although achieving a target dialyzer urea clearance does not equate with adequate clearance of other azotaemic toxins, inadequate urea clearance will increase uraemic toxin retention, so endangering normal physiologic function, leading to the uraemic syndrome and death. In addition to inadequate uremic solute clearance, if patients do not have sufficient RRF, then they will be at risk of fluid overload with less frequent regimes, and also excessive ultrafiltration requirements both of which may lead to more hospitalization and incur greater health care costs [37]. Although dehydration post-dialysis acutely reduces RRF, maintaining a higher extracellular volume does not only fail to preserve RRF [38] but may accelerate the loss of RRF and risks the consequences of extracellular volume expansion. Although current data suggests favourable RRF preservation with an incremental regime, there is no directed relationship between RRF and better patient survival $[36,39]$. A recent cohort study from the United States reported higher mortality in patients starting dialysis less than thrice weekly with a baseline urea clearance $\leq 3 \mathrm{~mL} / \mathrm{min} / 1.73 \mathrm{~m}^{2}$ or urine volume $\leq 600$ $\mathrm{mL} /$ day [10]. As such, twice-weekly HD schedules may not provide sufficient azotaemic solute control for such patients. In addition, more physically active patients with greater dietary protein intake will require greater clearances, compared to older more sedentary frail patients, and again may not be suitable for less frequent dialysis schedules [40]. Additionally, close monitoring of RRF, total urea clearance and hydration status is mandatory for less frequent regimes. Further prospective studies are re- quired to determine whether there are generalizable cutoff points to determine which patients should be offered less frequent HD schedules, and as RRF declines when HD schedules should best be increased.

\section{What Is Incremental HD?}

An incremental dialysis approach to initiating HD is to consider RRF and aim to achieve a composite total urea clearance target. As such, the amount of dialyzer clearance is increased to compensate for losses of RRF. It is important to note that incremental dialysis does not only apply to initiating HD but also includes the management of prevalent patients who have lost their RRF or have extracellular water excess, thereby increasing dialysis frequency, duration and considering HDF.

The main objective of starting with incremental dialysis is to preserve RRF. However, it should always be remembered that small solute clearance is only one aspect of patient management, and sodium balance, extracellular water retention, blood pressure control, bone and mineral disorders and acid-base control are also to be considered. Therefore, any dialysis regime should be adjusted to the needs of the individual patient. When patients have substantial RRF, then a less frequent, shorter session, smaller surface area dialyzer, slower blood or dialysate pump speeds and smaller needle size should be considered. On the other hand, when RRF has been lost, then introducing higher convective volume exchanges with online HDF, using a superflux dialyzer, or adding an adsorptive membrane or manipulating diet $[39,41]$ is a potential option to increase solute clearances.

In addition to standard clinical evaluation, the other keys to success are initiating patients on less frequent $\mathrm{HD}$ schedules that require regular monitoring of RRF and prompt intervention to adjust dialyzer clearance as RRF declines. In clinical practice, RRF is assessed by $24-\mathrm{h}$ urine urea or combined urea and creatinine clearance, which only represent glomerular function, and neglect renal tubular function, which is important for middlemolecule and protein-bound solute clearance. As such, adjusting dialyzer urea clearance solely based on urinary small solute clearance might not be the most appropriate clinical target. Moreover, 24-h or inter-dialytic urine collections increase costs, and increase workload on the dialysis centre staff, and are a burden to patients. Equally, not all patients are capable of collecting urine. Thus, there has been renewed interest in trying to develop serumbased RRF assessments. Two equations have been recent- 
ly proposed, using serum biomarkers including $\beta 2 \mathrm{M}$, $\beta$-trace protein and cystatin $C[42,43]$ and have been validated as a pragmatic technique for estimating RRF, and developing this approach will allow more dialysis centres offer an incremental dialysis approach.

\section{Incremental Regimes and Alternative Approaches to Preserve RRF}

A reduction in weekly dialysis time can be achieved by either shortening session times or reducing frequency. Despite an apparent equal weekly dialysis time, for example, 2-h thrice-weekly versus 3-h twice-weekly dialysis, these schedules result in different clearances. Shorter session times but more frequent dialysis reduces the time average concentration of small molecules, including urea and potassium, as these small solutes are readily cleared during the first hour of the dialysis session. Likewise, acidosis is also initially corrected by the movement of bicarbonate from the dialysate. In addition, the shorter interdialytic interval limits the accumulation of solutes and fluid retention, as such intra-dialytic electrolyte and osmotic changes are less and with lower ultrafiltration rates may consequently allow greater haemodynamic stability during dialysis. Avoiding intra-dialytic hypotension and cardiac arrhythmias is associated with the preservation of RRF [44], fewer cardiovascular events [45] and mortality [46]. Another potential advantage of a shorter dialysis session length is that recovery time may be faster, which is positively related to the quality of life and inversely related to hospitalization and mortality [47]. However, most azotaemic solutes are intracellular, and proteinbound solutes, both of which are cleared slowly, so tend to be retained with short dialysis schedules. Patients with high inter-dialytic weight gains are not suitable for short dialysis sessions, as they would require higher ultrafiltration rates, thereby increasing the risk of intra-dialytic hypotension, loss of RRF and mortality [48]. Longer dialysis session times but less frequent schedules are more effective for compartmental solute clearances, longer ultrafiltration time, less exposure to the extracorporeal circuit, fewer access cannulations, lower health care costs and more dialysis-free days. However, this approach may cause some patients to become symptomatic due to the greater intra-dialytic solute drop and longer recovery times and higher inter-dialytic weight gains with increased risk of inter-dialytic hypotension. Other incremental approaches such as using small-gauge fistula or graft needles along with slower blood pump speeds are likely to increase access survival [49], while slower dialysate pump speeds, using less dialysate or using smaller surface area dialyzers may reduce health care costs.

As the amount of dialysis required depends upon azotaemic solute generation, one group proposed the combination of a low-protein diet and once-weekly dialysis, and reported better preservation of RRF and nutritional status [39]. RRF increases the clearance of inflammatory cytokines and other mediators, which potentially may have helped to prevent malnutrition [50]. However, longerterm studies are required to determine whether patients would adhere to the diet, and short-term benefits could be sustained. Aside from dialysis adequacy, a longer inter-dialytic gap potentially risks greater fluid and sodium gains, with several studies reporting increased hospital admissions due to pulmonary oedema in thrice-weekly HD patients following the longer inter-dialytic interval [51]. As such, infrequent HD schedules should be avoided for patients with high inter-dialytic weight gains and those with cardiac failure.

Intra-dialytic hypotension is a major risk factor for the loss of RRF [22], and high ultrafiltration rates are associated with a greater risk of hypotension. Although there are many patient factors that predispose to intra-dialytic hypotension including impaired cardiac systolic and diastolic function and autonomic neuropathy, preventing excessive fluid removal by setting an appropriate postdialysis target weight is vitally important. In most centres, post-dialysis target weight is determined by clinical examination and review of blood pressure, pre- and postdialysis weights and intra-dialytic symptoms. More recent bioimpedance devices have been used to aid clinical assessment of volume status. However, studies have shown that using bioimpedance is prone to deplete intravascular volume, and as such reduce rather than preserve RRF $[52,53]$. Intra-dialytic hypotension can be reduced by simple cooling of the dialysate, with a recent metaanalysis reporting a $70 \%$ reduction in the rate of intradialytic hypotension and a $12 \mathrm{~mm} \mathrm{Hg}$ increase in the mean arterial pressure compared with standard dialysis [54]. However, not all patients can tolerate cooling. Stepwise dialysate sodium profiling can improve vascular refilling and has been reported to reduce intra-dialytic hypotension [55]. Although this may be effective in the short term, it risks sodium loading and increased interdialytic weight gains in the longer term. Other studies have reported that changing the ultrafiltration profile scan decreased hypotensive episodes [56]. Several studies have observed a reduced incidence of intra-dialytic hypotension with high volume online HDF. This may be due 
to the additional cooling effect of HDF [57], but this greater haemodynamic stability has been reported to better preserve RRF [58]. Acetate in the dialysate can potentially induce peripheral vasodilatation, cardiac dysfunction and an inflammatory response predisposing to intradialytic hypotension. Although most dialysates now contain 3-5 mEq/L of acetate, this has been suggested to have a clinical effect when infused as part of a large volume replacement fluid [59]. Implementation of acetatefree HDF potentially reduces the risk of intra-dialytic hypotension [60] after the long inter-dialytic interval, although this technique typically leads to a greater positive sodium balance, and has not been shown to provide greater cardiovascular stability compared to high-volume online HDF [61].

\section{Considerations of Incremental Dialysis}

HD is not limited to providing uremic toxin clearance but is also important in maintaining sodium balance and hydration status. Inadequate fluid and sodium removal increases the risk of volume overload, hypertension and ventricular hypertrophy [62]. Less frequent dialysis has been associated with more episodes of admission due to heart failure, fluid overload and pulmonary oedema, thereby increasing health care costs [37]. Moreover, maintaining overhydration status does not help preserve RRF $[38,52]$, and possibly increases the risk of loss of $\mathrm{RRF}$, as more rapid ultrafiltration may be required, resulting in more frequent and more profound hypotensive episodes. The main challenges of applying incremental dialysis are careful review with close monitoring of uraemic toxin clearance, fluid and electrolyte balance along with prompt modification of dialysis prescriptions. However, the concept of dialysis customization may increase dialysis staff workload, as urine collections and more assessments are required. On the other hand, less frequent dialysis schedules for some patients then allow others to undergo dialysis more frequently, and by varying dialysis session times it helps avoid staff pressures to start and end all patient treatments at the same time. Depending upon the health care system, incremental dialysis may or may not reduce dialysis centre reimbursement.

Although offering incremental dialysis potentially offers patients a better quality of life and preservation of $\mathrm{RRF}$, the assumption is that dialytic clearance is appropriately increased as RRF is lost. However, practising incremental dialysis without adjusting dialytic clearance po- tentially only leads to greater morbidity and mortality $[10,42]$. Appropriate patient selection, for instance, baseline urea clearance $>3 \mathrm{~mL} / \mathrm{min} / 1.73 \mathrm{~m}^{2}$ or urine volume $>600 \mathrm{~mL} /$ day [10], should be the first step to consider whether patients may be suitable for incremental dialysis before applying this regime to prevent further complications (Table 1).

\section{Dialysis Prescription for Patients without RRF}

When RRF declines, the primary concern is the adequacy of azotaemic toxin clearance. Clinical guidelines advise a minimum urea clearance target. However, the sessional spKt/Vurea only represents small solute clearance, and does not provide information about the clearance of slow-to-equilibrate solutes such as phosphate, middlemolecules and protein-bound toxins. As these solutes move more slowly between compartments, their clearance is time limited. Ideally, the development of portable or wearable or implantable HD devices would allow for prolonged treatment times that mimick continuous function of native kidneys, as such offer more efficient clearance [63]. Such devices would potentially not only improve blood pressure control, solute removal and fluid and electrolyte balance but would also allow greater physical activity, liberalize dietary intake and increase quality of life.

As expected, extending dialysis time results in the significant reduction of pre-dialysis, time average concentration and increasing dialyzer clearance of phosphate and $\beta 2 \mathrm{M}$ [64-66]. The weekly treatment time has a more pronounced effect on TAC $\beta 2 \mathrm{M}$ than frequency alone. Middle-molecule clearance has been used to define dialyzer membrane flux, and as such, $\beta 2 \mathrm{M}$ clearance is greater with high-flux dialyzers [67]. The HEMO study [3] reported a survival benefit for high-flux HD in prevalent patients with a dialysis vintage in excess of 3.7 years, so presumably those with little or no RRF [68]. An alternative approach to improve middle-molecule clearance is to add convective transport. HDF results in higher middlemolecule clearances than high-flux HD [69-71]. Post-dilution HDF is superior to pre-dilution HDF for $\beta 2 \mathrm{M}$ clearance but not different for protein-bound solute removal [72]. Online HDF provides greater convective volume exchange, with estimates of $0.6 \mathrm{mg} / \mathrm{L}$ reduction in serum $\beta 2 \mathrm{M}$ concentrations for each $10 \mathrm{~L}$ of additional weekly convection volume in anuric patients [73]. Although some reports have suggested that HDF provided greater protein-bound solute clearance than haemofiltration or high-flux $\mathrm{HD}$, the reductions in pre-dialysis se- 
Table 1. Suggested quality metric for patients treated by incremental haemodialysis

\begin{tabular}{ll}
\hline Measurement & Comment \\
\hline Serum creatinine & Monthly pre-dialysis serum creatinine is stable and not increasing \\
\hline Residual renal function & $\begin{array}{l}\text { 3 monthly urine volume } \\
\text { 3 monthly urea clearance } \\
\text { 6 monthly } \beta 2 \text { microglobulin }\end{array}$ \\
\hline Hydration status & Monthly clinical assessment of inter-dialytic weight gains and target weight \\
& Monthly assessment pre-dialysis blood pressure and intra-dialytic hypotension \\
& 3-monthly bioimpedance assessment of extracellular water \\
& 3-monthly cardiac natriuretic peptide \\
\hline Acid-base & Monthly pre-dialysis serum bicarbonate \\
\hline Nutritional status & Monthly serum albumin \\
& Monthly normalised protein accumulation rate \\
& Monthly serum urea and phosphate \\
6-monthly bioimpedance measurement lean body mass and fat mass
\end{tabular}

rum concentrations were small and not thought to be sufficient to improve clinical outcomes $[72,74]$. As studies show increased $\beta 2 \mathrm{M}$ clearance with online HDF and more frequent longer HD schedules, these should be the preferred options for HD patients without RRF.

Simply increasing dialysate flow and dialyzer surface area was reported to augment protein-bound solute clearance [75]; however, overall clearance remained low. A newer generation of highly permeable or "high cutoff" or "superflux" dialyzer, which have larger pore sizes, with a molecular weight cut-off point up to $65 \mathrm{kDa}$, has been developed, although reporting greater effective clearance of myoglobin [76], free light chains [77] and cytokines [78]; any benefit in terms of clearing proteinbound toxins has to be traded off against increased albumin losses [78]. Advances in membrane technology led to the development of novel dialyzers with enhanced protein-bound solute clearance by adsorption. Some of the hydrophobic membrane polymers such as polysulfone and polymethylmethacrylate (PMMA) have the affinity to adsorb proteins. Although a PMMA-based protein-leaking membrane showed a significant reduction of pre-dialysis total homocysteine concentration [79], increasing membrane fouling by protein deposition might compromise other solute clearances over time. Experimentally novel mix-matrix membranes, in which adsorptive particles are incorporated into a macro-po- rous membrane layer with particle-free membrane layer on the blood-contacting side of the membrane has been developed, and trials have demonstrated the ability to remove protein-bound solutes [80]. In Japan, sorbent cartridges are used to increase $\beta 2 \mathrm{M}$ removal [81]. However, direct contact between blood and sorbents might lead to leukopenia, thrombocytopenia and embolization. An alternative approach is to add the sorbent into the dialysate, and experimental reports have suggested increased protein-bound solute removal $[82,83]$. An alternative approach has been to try and displace proteinbound toxins by infusing hypertonic saline or docosahexaenoic acid to disrupt electrostatic binding [83, 84]. Although studies have shown that this is possible, the additional removal has been marginal, and longer-term safety studies are required to ensure that hypertonic saline or docosahexaenoic acid are not returned to the patient.

\section{Conclusion}

Incremental dialysis requires a dynamic approach by considering the patient and adjusting the dialysis treatment according to their clinical needs and RRF. However, as clinical circumstances and RRF change over time, this requires adjustments to dialysis treatments to maintain 
Fig. 1. Incremental dialysis model.

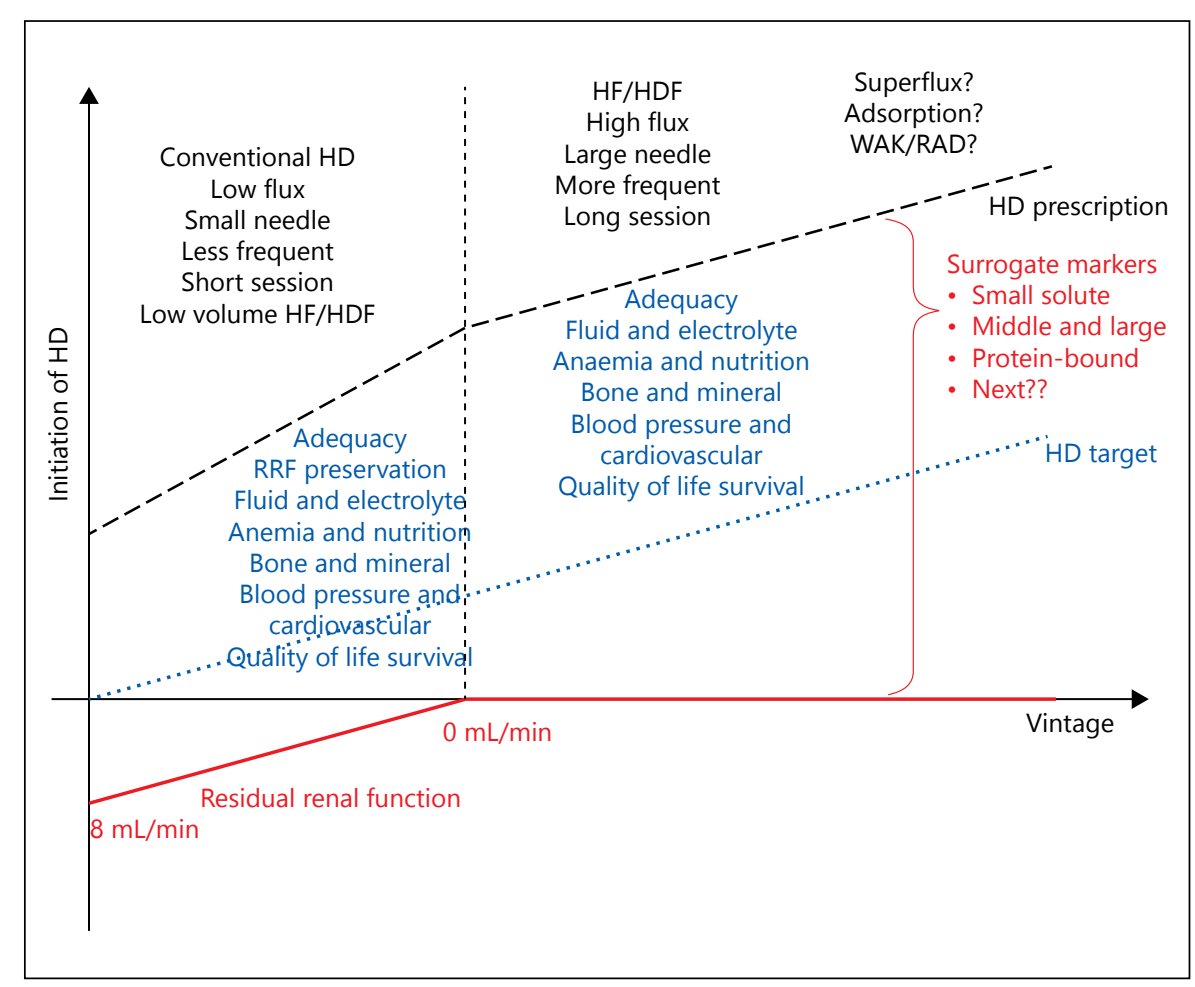

solute clearance targets and extracellular volume control (Fig. 1). Applying a single fixed regime to everyone regardless of clinical status and individual requirements is potentially harmful. Among patients with substantial RRF, it is important to tailor dialysis methods and avoid intra-dialytic hypotension to preserve RRF. However, an incremental dialysis approach introduces additional workload, as there has to be regular clinical assessments and RRF has to be periodically measured to avoid compromising other clinical aspects and inadequate dialysis. When patients lose their RRF, then although small solute dialysis adequacy has become the main target, these patients need changes to their dialysis prescription to im- prove middle-molecule and protein-bound solute removal by escalating dialysis session times and considering high volume online HDF or other alternatives.

\section{Disclosure Statement}

The authors have no financial interests to disclose.

\section{Funding}

Dr. Tangvoraphonkchai was awarded an International Society of Nephrology clinical fellowship.

\section{References}

1 Robinson BM, Akizawa T, Jager KJ, Kerr PG, Saran R, Pisoni RL: Factors affecting outcomes in patients reaching end-stage kidney disease worldwide: differences in access to renal replacement therapy, modality use, and haemodialysis practices. Lancet 2016;388: 294-306.

2 Gotch FA, Sargent JA: A mechanistic analysis of the National Cooperative Dialysis Study (NCDS). Kidney Int 1985;28:526-534.

3 Eknoyan G, Beck GJ, Cheung AK, Daugirdas JT, Greene T, Kusek JW, et al: Effect of dialysis dose and membrane flux in maintenance hemodialysis. N Engl J Med 2002;347:2010-2019.

4 Meyer TW, Sirich TL, Fong KD, Plummer NS, Shafi T, Hwang S, et al: Kt/Vurea and nonurea small solute levels in the hemodialysis study. J Am Soc Nephrol 2016;27:34693478.

5 Lowrie EG, Laird NM, Parker TF, Sargent JA: Effect of the hemodialysis prescription of patient morbidity: report from the National Cooperative Dialysis Study. N Engl J Med 1981; 305:1176-1181.
6 Locatelli F, Martin-Malo A, Hannedouche T, Loureiro A, Papadimitriou M, Wizemann V, et al: Effect of membrane permeability on survival of hemodialysis patients. J Am Soc Nephrol 2009;20:645-654.

7 Peters SA, Bots ML, Canaud B, Davenport A, Grooteman MP, Kircelli F, et al: Haemodiafiltration and mortality in end-stage kidney disease patients: a pooled individual participant data analysis from four randomized controlled trials. Nephrol Dial Transplant 2016; 31:978-984. 
8 Farrington K, Davenport A: Would prescribing target Kt dose adjusted for body surface area improve hemodialysis outcomes? Kidney Int 2016;90:1160-1162.

9 Sirich TL, Meyer TW, Gondouin B, Brunet P, Niwa T: Protein-bound molecules: a large family with a bad character. Semin Nephrol 2014;34:106-117.

10 Obi Y, Streja E, Rhee CM, Ravel V, Amin AN, Cupisti A, et al: Incremental hemodialysis, residual kidney function, and mortality risk in incident dialysis patients: a cohort study. Am J Kidney Dis 2016;68:256-265.

11 Scribner BH, Cole JJ, Ahmad S, Blagg CR: Why thrice weekly dialysis? Hemodial Int 2004;8:188-192.

12 Davenport A, Hussain Sayed R, Fan S: The effect of racial origin on total body water volume in peritoneal dialysis patients. Clin J Am Soc Nephrol 2011;6:2492-2498.

13 Sridharan S, Vilar E, Davenport A, Ashman $\mathrm{N}$, Almond M, Banerjee A, et al: Scaling hemodialysis target dose to reflect body surface area, metabolic activity, and protein catabolic rate: a prospective, cross-sectional study. Am J Kidney Dis 2017;69:358-366.

14 Merkus MP, Jager KJ, Dekker FW, de Haan RJ, Boeschoten EW, Krediet RT: Predictors of poor outcome in chronic dialysis patients: the Netherlands cooperative study on the adequacy of dialysis. The NECOSAD study group. Am J Kidney Dis 2000;35:69-79.

15 Wang AY, Wang M, Woo J, Law MC, Chow $\mathrm{KM}$, Li PK, et al: A novel association between residual renal function and left ventricular hypertrophy in peritoneal dialysis patients. Kidney Int 2002;62:639-647.

16 Roumelioti ME, Nolin T, Unruh ML, Argyropoulos C: Revisiting the middle molecule hypothesis of uremic toxicity: a systematic review of beta 2 microglobulin population kinetics and large scale modeling of hemodialysis trials in silico. PLoS One 2016; 11:e0153157.

17 Sirich TL, Fong K, Larive B, Beck GJ, Chertow $\mathrm{GM}$, Levin NW, et al: Limited reduction in uremic solute concentrations with increased dialysis frequency and time in the frequent hemodialysis network daily trial. Kidney Int 2017;pii:S0085-2538(16)30648-2.

18 Maduell F, Moreso F, Pons M, Ramos R, Mora-Macia J, Carreras J, et al: High-efficiency postdilution online hemodiafiltration reduces all-cause mortality in hemodialysis patients. J Am Soc Nephrol 2013;24:487-497.

19 Kandouz S, Mohamed AS, Zheng Y, Sandeman S, Davenport A: Reduced protein bound uraemic toxins in vegetarian kidney failure patients treated by haemodiafiltration. Hemodial Int 2016;20:610-617.

20 Daugirdas JT, Greene T, Rocco MV, Kaysen GA, Depner TA, Levin NW, et al: Effect of frequent hemodialysis on residual kidney function. Kidney Int 2013;83:949-958.

21 Lin YF, Huang JW, Wu MS, Chu TS, Lin SL, Chen YM, et al: Comparison of residual renal function in patients undergoing twice-weekly versus three-times-weekly haemodialysis. Nephrology (Carlton) 2009;14:59-64.

22 Zhang M, Wang M, Li H, Yu P, Yuan L, Hao $\mathrm{C}$, et al: Association of initial twice-weekly hemodialysis treatment with preservation of residual kidney function in ESRD patients. Am J Nephrol 2014;40:140-150.

23 Grantham JJ, Wallace DP: Return of the secretory kidney. Am J Physiol Renal Physiol 2002;282:F1-F9.

24 Suri RS, Larive B, Sherer S, Eggers P, Gassman J, James SH, et al: Risk of vascular access complications with frequent hemodialysis. J Am Soc Nephrol 2013;24:498-505.

25 Lee T, Roy-Chaudhury P: Advances and new frontiers in the pathophysiology of venous neointimal hyperplasia and dialysis access stenosis. Adv Chronic Kidney Dis 2009;16: 329-338.

26 Jun M, Jardine MJ, Gray N, Masterson R, Kerr PG, Agar JW, et al: Outcomes of extendedhours hemodialysis performed predominantly at home. Am J Kidney Dis 2013;61:247253.

27 Herbelin A, Urena P, Nguyen AT, Zingraff J, Descamps-Latscha B: Influence of first and long-term dialysis on uraemia-associated increased basal production of interleukin- 1 and tumour necrosis factor alpha by circulating monocytes. Nephrol Dial Transplant 1991;6: 349-357.

28 Herbelin A, Urena P, Nguyen AT, Zingraff J, Descamps-Latscha B: Elevated circulating levels of interleukin-6 in patients with chronic renal failure. Kidney Int 1991;39:954-960.

29 Donati D, Degiannis D, Raskova J, Raska K Jr: Uremic serum effects on peripheral blood mononuclear cell and purified T lymphocyte responses. Kidney Int 1992;42:681-689.

30 Stachowski J, Pollok M, Burrichter H, Spithaler C, Baldamus CA: Signalling via the TCR/ CD3 antigen receptor complex in uremia is limited by the receptors number. Nephron 1993;64:369-375.

31 Nissenson AR, Fine RN: Clinical Dialysis, ed 4. New York, McGraw-Hill Medical Publishing Division, 2005, pp xviii, 1169.

32 Weinhandl ED, Liu J, Gilbertson DT, Arneson TJ, Collins AJ: Survival in daily home hemodialysis and matched thrice-weekly incenter hemodialysis patients. J Am Soc Nephrol 2012;23:895-904.

33 Daugirdas JT, Chertow GM, Larive B, Pierratos A, Greene T, Ayus JC, et al: Effects of frequent hemodialysis on measures of $\mathrm{CKD}$ mineral and bone disorder. J Am Soc Nephrol 2012:23:727-738.

34 Poulsen CG, Kjaergaard KD, Peters CD, Jespersen B, Jensen JD: Quality of life development during initial hemodialysis therapy and association with loss of residual renal function. Hemodial Int 2016, Epub ahead of print.

35 Shafi T, Jaar BG, Plantinga LC, Fink NE, Sadler JH, Parekh RS, et al: Association of residual urine output with mortality, quality of life, and inflammation in incident hemodialy- sis patients: the choices for healthy outcomes incaringforend-stagerenaldisease (CHOICE) study. Am J Kidney Dis 2010;56:348-358.

36 Park JI, Park JT, Kim YL, Kang SW, Yang $\mathrm{CW}$, Kim NH, et al: Comparison of outcomes between the incremental and thrice-weekly initiation of hemodialysis: a propensitymatched study of a prospective cohort in Korea. Nephrol Dial Transplant 2017;32:355363.

37 Arneson TJ, Liu J, Qiu Y, Gilbertson DT, Foley RN, Collins AJ: Hospital treatment for fluid overload in the Medicare hemodialysis population. Clin J Am Soc Nephrol 2010;5: 1054-1063.

38 Davenport A, Sayed RH, Fan S: Is extracellular volume expansion of peritoneal dialysis patients associated with greater urine output? Blood Purif 2011;32:226-231.

39 Caria S, Cupisti A, Sau G, Bolasco P: The incremental treatment of ESRD: a low-protein diet combined with weekly hemodialysis may be beneficial for selected patients. BMC Nephrol 2014;15:172.

40 El-Kateb S, Sridharan S, Farrington K, Fan S, Davenport A: A single weekly Kt/Vurea target for peritoneal dialysis patients does not provide an equal dialysis dose for all. Kidney Int 2016;90:1342-1347.

41 Bolasco P, Cupisti A, Locatelli F, Caria S, Kalantar-Zadeh K: Dietary management of incremental transition to dialysis therapy: onceweekly hemodialysis combined with low-protein diet. J Ren Nutr 2016;26:352-359.

42 Shafi T, Michels WM, Levey AS, Inker LA, Dekker FW, Krediet RT, et al: Estimating residual kidney function in dialysis patients without urine collection. Kidney Int 2016;89: 1099-1110.

43 Wong J, Sridharan S, Berdeprado J, Vilar E, Viljoen A, Wellsted D, et al: Predicting residual kidney function in hemodialysis patients using serum beta-trace protein and beta2-microglobulin. Kidney Int 2016;89: 1090-1098.

44 Jansen MA, Hart AA, Korevaar JC, Dekker FW, Boeschoten EW, Krediet RT, et al: Predictors of the rate of decline of residual renal function in incident dialysis patients. Kidney Int 2002;62:1046-1053.

45 Verde E, Perez de Prado A, Lopez-Gomez JM, Quiroga B, Goicoechea M, Garcia-Prieto A, et al: Asymptomatic intradialytic supraventricular arrhythmias and adverse outcomes in patients on hemodialysis. Clin J Am Soc Nephrol 2016;11:2210-2217.

46 Fujii H, Kim JI, Yoshiya K, Nishi S, Fukagawa $\mathrm{M}$ : Clinical characteristics and cardiovascular outcomes of hemodialysis patients with atrial fibrillation: a prospective follow-up study. Am J Nephrol 2011;34:126-134.

47 Rayner HC, Zepel L, Fuller DS, Morgenstern $\mathrm{H}$, Karaboyas A, Culleton BF, et al: Recovery time, quality of life, and mortality in hemodialysis patients: the Dialysis Outcomes and Practice Patterns Study (DOPPS). Am J Kidney Dis 2014;64:86-94. 
48 Flythe JE, Curhan GC, Brunelli SM: Shorter length dialysis sessions are associated with increased mortality, independent of body weight. Kidney Int 2013;83:104-113.

49 Asano M, Thumma J, Oguchi K, Pisoni RL, Akizawa T, Akiba T, et al: Vascular access care and treatment practices associated with outcomes of arteriovenous fistula: international comparisons from the Dialysis Outcomes and Practice Patterns Study. Nephron Clin Pract 2013;124:23-30.

50 Wang AY, Lai KN: The importance of residual renal function in dialysis patients. Kidney Int 2006;69:1726-1732.

51 Fotheringham J, Fogarty DG, El Nahas M, Campbell MJ, Farrington K: The mortality and hospitalization rates associated with the long interdialytic gap in thrice-weekly hemodialysis patients. Kidney Int 2015;88:569575.

52 McCafferty K, Fan S, Davenport A: Extracellular volume expansion, measured by multifrequency bioimpedance, does not help preserve residual renal function in peritoneal dialysis patients. Kidney Int 2014;85:151-157.

53 Rhee H, Baek MJ, Chung HC, Park JM, Jung WJ, Park SM, et al: Extracellular volume expansion and the preservation of residual renal function in Korean peritoneal dialysis patients: a long-term follow up study. Clin Exp Nephrol 2016;20:778-786.

54 Mustafa RA, Bdair F, Akl EA, Garg AX, Thiessen-Philbrook H, Salameh H, et al: Effect of lowering the dialysate temperature in chronic hemodialysis: a systematic review and metaanalysis. Clin J Am Soc Nephrol 2016;11:442457.

55 Dunne N: A meta-analysis of sodium profiling techniques and the impact on intradialytic hypotension. Hemodial Int 2016, Epub ahead of print.

56 Zhou YL, Liu HL, Duan XF, Yao Y, Sun Y, Liu Q: Impact of sodium and ultrafiltration profiling on haemodialysis-related hypotension. Nephrol Dial Transplant 2006;21:3231-3237.

57 Donauer J, Schweiger C, Rumberger B, Krumme B, Bohler J: Reduction of hypotensive side effects during online-haemodiafiltration and low temperature haemodialysis. Nephrol Dial Transplant 2003;18:1616-1622.

58 Hyodo T, Koutoku N: Preservation of residual renal function with HDF. Contrib Nephrol 2011;168:204-212.

59 Pizzarelli F, Cerrai T, Dattolo P, Ferro G: On-line haemodiafiltration with and without acetate. Nephrol Dial Transplant 2006;21: 1648-1651.

60 Tessitore N, Santoro A, Panzetta GO, Wizemann V, Perez-Garcia R, Martinez Ara J, et al: Acetate-free biofiltration reduces intradialytic hypotension: a European multicenter ran- domized controlled trial. Blood Purif 2012;34: 354-363.

61 Ding F, Ahrenholz P, Winkler RE, Ramlow W, Tiess M, Michelsen A, et al: Online hemodiafiltration versus acetate-free biofiltration: a prospective crossover study. Artif Organs 2002;26:169-180.

62 Fagugli RM, Pasini P, Quintaliani G, Pasticci F, Ciao G, Cicconi B, et al: Association between extracellular water, left ventricular mass and hypertension in haemodialysis patients. Nephrol Dial Transplant 2003;18: 2332-2338.

63 Fissell WH, Roy S, Davenport A: Achieving more frequent and longer dialysis for the majority: wearable dialysis and implantable artificial kidney devices. Kidney Int 2013;84:256264.

64 Basile C, Libutti P, Di Turo AL, Casino FG, Vernaglione L, Tundo S, et al: Removal of uraemic retention solutes in standard bicarbonate haemodialysis and long-hour slowflow bicarbonate haemodialysis. Nephrol Dial Transplant 2011;26:1296-1303.

65 Eloot S, Van Biesen W, Dhondt A, Van de Wynkele H, Glorieux G, Verdonck P, et al: Impact of hemodialysis duration on the removal of uremic retention solutes. Kidney Int 2008;73:765-770.

66 Raj DS, Ouwendyk M, Francoeur R, Pierratos A: beta(2)-microglobulin kinetics in nocturnal haemodialysis. Nephrol Dial Transplant 2000;15:58-64.

67 Leypoldt JK, Cheung AK, Deeter RB: Rebound kinetics of beta2-microglobulin after hemodialysis. Kidney Int 1999;56:15711577.

68 Leypoldt JK, Meijers BK: Effect of treatment duration and frequency on uremic solute kinetics, clearances and concentrations. Semin Dial 2016;29:463-470.

69 Lornoy W, Becaus I, Billiouw JM, Sierens L, van Malderen P: Remarkable removal of beta2-microglobulin by on-line hemodiafiltration. Am J Nephrol 1998;18:105-108.

70 Maduell F, Navarro V, Cruz MC, Torregrosa E, Garcia D, Simon V, et al: Osteocalcin and myoglobin removal in on-line hemodiafiltration versus low- and high-flux hemodialysis. Am J Kidney Dis 2002;40:582-589.

71 Ward RA, Schmidt B, Hullin J, Hillebrand GF, Samtleben W: A comparison of on-line hemodiafiltration and high-flux hemodialysis: a prospective clinical study. J Am Soc Nephrol 2000;11:2344-2350.

72 Meert N, Eloot S, Waterloos MA, Van Landschoot M, Dhondt A, Glorieux G, et al: Effective removal of protein-bound uraemic solutes by different convective strategies: a prospective trial. Nephrol Dial Transplant 2009; 24:562-570.
73 Canaud B, Barbieri C, Marcelli D, Bellocchio F, Bowry S, Mari F, et al: Optimal convection volume for improving patient outcomes in an international incident dialysis cohort treated with online hemodiafiltration. Kidney Int 2015;88:1108-1116.

74 Bammens B, Evenepoel P, Verbeke K, Vanrenterghem Y: Removal of the protein-bound solute $\mathrm{p}$-cresol by convective transport: a randomized crossover study. Am J Kidney Dis 2004;44:278-285.

75 Sirich TL, Luo FJ, Plummer NS, Hostetter TH, Meyer TW: Selectively increasing the clearance of protein-bound uremic solutes. Nephrol Dial Transplant 2012;27:1574-1579.

76 Heyne N, Guthoff M, Krieger J, Haap M, Haring HU: High cut-off renal replacement therapy for removal of myoglobin in severe rhabdomyolysis and acute kidney injury: a case series. Nephron Clin Pract 2012;121:c159c164.

77 Kirsch AH, Lyko R, Nilsson LG, Beck W, Amdahl M, Lechner P, et al: Performance of hemodialysis with novel medium cut-off dialyzers. Nephrol Dial Transplant 2017;32:165172.

78 Villa G, Zaragoza JJ, Sharma A, Neri M, De Gaudio AR, Ronco C: Cytokine removal with high cut-off membrane: review of literature. Blood Purif 2014;38:167-173.

79 Galli F, Benedetti S, Buoncristiani U, Piroddi $\mathrm{M}$, Conte C, Canestrari F, et al: The effect of PMMA-based protein-leaking dialyzers on plasma homocysteine levels. Kidney Int 2003; 64:748-755.

80 Tijink MS, Wester M, Glorieux G, Gerritsen KG, Sun J, Swart PC, et al: Mixed matrix hollow fiber membranes for removal of proteinbound toxins from human plasma. Biomaterials 2013;34:7819-7828.

81 Kruse A, Tao X, Bhalani V, Handelman G, Levin NW, Kotanko P, et al: Clearance of pcresol sulfate and $\beta$-2-microglobulin from dialysate by commercially available sorbent technology. ASAIO J 2011;57:219-224.

82 Meyer TW, Peattie JW, Miller JD, Dinh DC, Recht NS, Walther JL, et al: Increasing the clearance of protein-bound solutes by addition of a sorbent to the dialysate. J Am Soc Nephrol 2007;18:868-874.

83 Krieter DH, Devine E, Korner T, Ruth M, Wanner C, Raine M, et al: Haemodiafiltration at increased plasma ionic strength for improved protein-bound toxin removal. Acta Physiol (Oxf) 2017;219:510-520.

84 Tao X, Thijssen S, Kotanko P, Ho CH, Henrie M, Stroup E, et al: Improved dialytic removal of protein-bound uraemic toxins with use of albumin binding competitors: an in vitro human whole blood study. Sci Rep 2016;6: 23389. 